\title{
Integrating Reading and Technology: The Development of Pamanpintermu
}

\author{
Yudhi Arifani ${ }^{1} \&$ Harunur Rosyid ${ }^{2}$ \\ ${ }^{1}$ English Department, University of Muhammadiyah Gresik, Indonesia \\ 2 Informatics Department, University of Muhammadiyah Gresik, Indonesia \\ Correspondence: Yudhi Arifani, English Department University of Muhammadiyah Gresik, Jl. Sumatera 101 \\ GKB Randuagung, Gresik, Indonesia. Tel: 62-813-2741-8413. E-mail: yudhiarif_76@yahoo.co.id
}

\author{
Received: August 21, 2016 Accepted: September 25, 2016 Online Published: September 27, 2016 \\ doi: 10.5539/elt.v9n11p13 URL: http://dx.doi.org/10.5539/elt.v9n11p13
}

\begin{abstract}
Reading as one of English skills has paramount features in shaping EFL English competence. Referring to the importance for reading, it is inevitable that teaching method, assessments tools, reading material and activities have indispensable tasks to attain EFL learners' reading objectives. This study is intended to develop integrated reading material using PHP software. It is designed to react toward the vast development of technology and to reach the attainment of more comprehensive reading objectives in accordance with International Reading Association's views which is not achieved yet in today's EFL teaching context. The study utilizes five phases Research and Development model covering need analysis, design, development, Focus Group Discussion and Try out. The development invented 10 units of reading material within Pamanpintermu's program containing audio vocabulary survey, timed reading, audio reading, comprehension task, writing sections and its integrated auto assessment devices in every unit. The results from FGD and try out revealed that the theoretical foundation and syntax were categorized into high as it reached the average score of 3.7. In addition, content relevance achieved the average score of 3.9 as high and difficulty level reached 2.3 as medium. Meanwhile, the category of integrated reading skills and auto scoring obtained 3.6 and 3.8 and both categories belonged to high level. The last point, software practicality achieved 3.5 is very high as it is also applicable for teacher made reading material automatically through modifying the reading text, audio, exercises and score thoroughly. Toward overall astonishing prototype Pamanpintermu, it remains one problematic point on the error reading detector section which cannot detect users' errors reading automatically as it requires intensive investigation from different background field of studies.
\end{abstract}

Keywords: reading, technology and Pamanpintermu

\section{Introduction}

Reading has significant donation toward the evolution of students' English mastery. It is undeniable that from reading, students' listening, speaking, writing, vocabulary, pronunciation and grammar can be enhanced through reading (Al-Seghayer, 2013; Arena \& Jefferson, 2008; Gonzales, 2007; Halic et al., 2010; Luu \& Nguyen, 2010; Peterson, 2012; Smidt \& Hegelheimer, 2004; Yoon, 2008). Regarding its powerful significance, the implementation of teaching reading has to be handled very carefully to address all the above essential elements. Therefore, teaching reading objectives, method, materials, media, and assessment international reading/literacy association. In today's digital era brings rapid impact toward the changes of the role of teachers, teaching strategy and reading material itself.

Many researchers claimed on the advantages of technology in EFL reading classes. Most of the benefits of technology on reading class perform in the aspects of motivation, interactivity, authentic material, learners' autonomy, automatic feedback, and thinking skills (Ahmed, 2015; Pop, 2010; Ravicandran et al., 2000, Sarica \& Cavus, 2009; Warshauver \& Healey, 1998).

Regarding the advantages of technology in EFL reading classes fruitful critics are addressed toward the existence of Computer Assisted Language Learning (CALL). Jarvis and Krashen (2014) toward the obsolete of CALL and its divisions need to be carefully considered. One of the critics lays on the term Computer within the terms CALL which cannot shadow today's vast development of mobile devices in language learning. Further, Jarvis 
and Achilleos (2013) offer the alteration of CALL into Mobile Assisted Language Use as a response toward the shortcoming of CALL on which merely rely on desktop and even laptop computers where MALU offers the more flexible one.

In responding toward one of the proposed critics, studies on mobile application have been raised as a warm issue in today's mobile ages. Mobile Assisted Language Learning (MALL) has also been developed such as by Chinnery (2006) and Chen and Hsu (2008) to enhance students' vocabulary mastery. Although the study of MALU and MALL are considered still immature toward learning theories (Naismith et al. 2004) but many probes have been investigated to toward the effectiveness of mobile application toward reading (Fisher et al., 2009; Hazea \& Alzubi, 2016, Demouy et al., 2011).

This research is developed to react toward the implementation of traditional reading paradigm at Indonesian EFL settings and to promote effective teaching and learning reading through the development of integrated reading material and the digital program. Empirical study shows that the implementation of traditional teaching and learning reading is dominant in EFL classroom settings. Most EFL teachers treat classroom reading into read, correct and question individually. As part of integrated English skills so reading is almost neglected due to less reading practice with twice in a week within one and half hour in each meeting. Ironically, with around thirty up to forty students in on class, a passage with approximately 400-700 words is applied for the whole 30 to 40 students in one meeting for the purpose of improving students' reading skill and comprehension. In addressing the purpose of reading skill, the teacher points out one student to read in turn one by one just for one or two sentences from the whole class and sometimes the teacher corrects student' reading errors one by one as well. Meanwhile, other students may do not have opportunity to practice their reading skill in the classroom. Afterward, reading comprehension is conducted by delivering comprehension question and discussion either individually or collaboratively. Consequently, not all students are able to achieve and learn the objective of reading skill, fluency and comprehension effectively.

Conversely, on the other sides, all reading objectives such as speed, skill/fluency, comprehension, phonetics, phonemics, and vocabulary text have to be learned simultaneously. Regarding the above notions, the roles of technology in handling individual reading can be boosted through a mobile reading software to facilitate not only students' reading fluency, speed, comprehension, vocabulary but also EFL teachers monitor individual reading through the mobile reading software to assess students' reading mastery so that feedback can be addressed appropriately.

Based on the above reason, this study attempts to design an integrated reading material and instrument using Mobile Use (MU) program to address the existing gap in the foregoing research. It is also developed to bridge EFL teachers' and learners' needs on the integration of technology and reading into mobile reading program at EFL contexts.

\section{Literature Review}

In line with the objective of the study this paper reviews previous research on the use of technology toward the development of reading and its implementation in the teaching and learning process.

\subsection{Issues on the Implementation of Computer Assisted Language Learning}

Issues on the implementation of computer assisted language learning lays content, program design, and effectiveness of CALL in the EFL teaching and learning. Several researchers study on the use of Computer Assisted Language Learning (CALL). One of the eminent reading and computer development is conducted by Nadera (2001). Several reading softwares are developed such as highlight words from text computer software, select logical option, prescriptive reading software, and gap kit software. Then, within the following ten years, Barraza (2014) utilizes computer based software named as interactive graphic organizer toward the engineering students. They are assigned to identify cause and effect, organizing sequence of events, and indentifying pros and cons through the computer. The finding indicates that it is very effective for improving students' reading score as well as offering new enjoyment via the software. Although the development concepts of the above software denote objective test format but their studies are able to address EFL teachers and students toward the vast existence of technology.

In accordance with the significance CALL and reading, Brett (2004) and Stockwell (2007) state that students' pronunciation mastery can be improved through CALL as it provides flexibility where students can do self-pronunciation training. Meanwhile, other researchers successfully address on the significance of CALL toward vocabulary learning (Al-Seghayer, 2001; Becker's, 2001; Ma \& Kelly, 2006). Toward the development of language skills (Grgurovic, 2007; Montero-Fleta \& Perez-Sabater, 2010) have already probed for its 
significances toward the improvement of students' language skill through the implementation of CALL.

\subsection{Issues on the Implementation of Mobile Assisted Language Use/Learning}

Mobile Assisted Language Use/Learning (MALU/MALL) emerges as a response toward the mushrooming growth of mobile technologies where previously technology is merely dominated by computer programs. The high demand toward the growth of mobile technologies, researchers have to move their focus toward EFL reading through CALL into mobile reading technology which can be used not only in computer but also in smart phones and tablet. The utilization of mobile technology in reading is embodied in the form of Whatsapp, online and offline dictionary which can facilitate learners with discussion, sharing ideas, and free reading practices through the gadgets. One of the well-known mobile programs is developed by Wang and Smith (2013) introduces reading and grammar via mobile phones. Students get positive experiences from their hand phone as they regularly get reading and grammar into their hand phone. Next, Kennedy and Levy (2008) probes the use of SMS for learning reading by sending a message with familiar and unfamiliar vocabulary simultaneously.

Toward the effectiveness of Mobile technology, two current studies revealed positive effects on students' reading comprehension. The first study conducted by Hazaera and Alzubi (2016) search the efficiency of utilizing mobile technology in EFL reading class in Najran University using mixed method approach showed that students' reading participation practices and text comprehension are improved. In addition, a study conducted by Foomami and Hedayati (2016) revealed similar results whereas in their study, students' perception toward seamless mobile technology can improve students' learning autonomy as well.

\subsection{Issues toward CALL and MALL}

Regardless of the merits of CALL and MALL in today's EFL teaching and learning, one of an everlasting issues is authentic versus non authentic reading materials. In mediating this issue, Arifani (2016) suggests careful reading material construction has to be considered to fulfil text readability, cultural appropriateness and comprehensible input issue, curriculum match where not all EFL learners get contact with all native settings. Another incoming issue is address by Jarvis and Krashen (2014) toward CALL and the issue of comprehensible inputs through unconscious learning. Further, they introduced more reasonable terms toward the word computer which does not optimize acquisition compare to the term mobile language assisted language leaning (MALL) which potentially good for language learning (Jarvis \& Achilleos, 2013).

By looking at the previous studies and issues on the integration of CALL, MALL and its other similar types, it is found that there have been little studies when it arrives into the integrated English skills for the teaching and learning English in EFL setting. Current studies rely much on separate English skills or component used in mobile technology which is not develop into EFL curriculum and context appropriately. This study is developed as a response toward the needs of integrated reading skills using offline and online mobile reading software for EFL settings.

\section{Method}

\subsection{Research Design}

This research utilized Research and Development (R\&D) model initiated by McGriff (2000) as it endeavoured to develop an integrated personal homepage (PHP) reading software material and its assessment instrument through mobile use named as Pamanpintermu. The development process encompassed five phases. First, need analysis on reading objectives, learning strategies, materials, assessment model and the need of mobile use program were addressed. Second, designing modified reading syllabus was formulated via reviewing the existing syllabus and the results of need analysis, reading material, exercises, assessment and mobile use software. Third, Prototype development was crafted in the form of audio vocabulary survey with its auto assessment and scoring. Audio reading skill and speed reading were created to have double function both as listening and reading comprehension with each manual assessment and auto-scoring. Vocabulary exercises, reading comprehension questions and writing activities were also accomplished using PHP software. Fourth, Focus Group Discussion (FGD) is executed for the sake of validation and revision toward the developed prototype. Fifth, the tryout of the developed prototype was then implemented. Finally, integrated reading software and its auto-assessment named as Pamanpintermu was invented. The following Figure 1 depicted each phase of the development. 


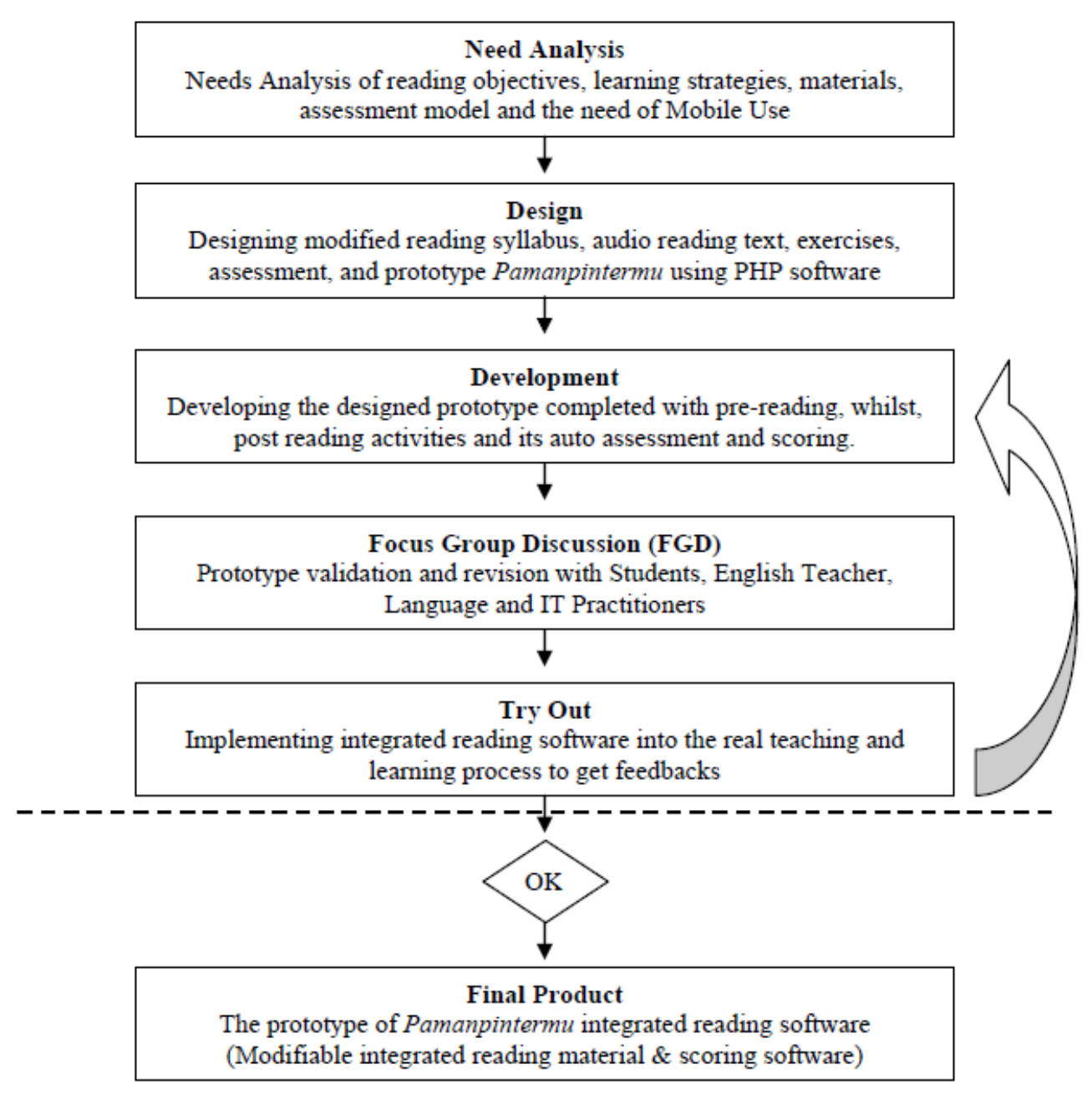

Figure 1. Development phases of Pamanpintermu integrated reading

\subsection{Need Analysis Phase}

Open-ended questionnaire consisting 10 items question were distributed to 110 respondents from two exemplary senior high schools in Gresik, namely SMAN 1 Gresik and SMA Muhammadiyah 1 Gresik. The questionnaires were distributed directly into each school after the researcher and his team got approval from the school principal. The distribution of the questionnaires was handled by the researcher, his team and the English teachers from each school directly after the teacher and learning process took place. It took at around one hour to fill the questionnaires both from the English teachers and students. The questionnaire was aimed at generating students' and English teachers' learning and Moreover, informal interview and discussion were also carried out with 2 IT experts under the specification of Java, PHP and Multimedia program to address the needs of mobile use program and to formulate relevant integrated reading software. Design Phase

In this phase, the writer designed modified syllabus by reviewing the previous syllabus and the result of need analysis. The syllabus depicted standard of competence, basic competence, indicators, teaching objectives, reading material, text difficulty level, reading exercises, vocabulary, writing exercises, audio, auto assessment and scoring model.

\subsection{Development Phase}

The developed prototype of Pamanpintermu under PHP program was then elaborated according to the preceding design. The development consisted of timed vocabulary survey as part of pre-reading section, vocabulary audio, and its auto vocabulary scoring model. The second development related to the elaboration of reading text, audio for listening and reading purposes, timed reading, dictionary text (DITEXT), manual scoring for reading errors and speed. The third development was three different models of comprehensions tasks completed with auto 
scoring. The fourth development was writing task taken from the passage. It introduced word formation and derivation construction with its auto scoring as well.

\subsection{Focus Group Discussion and Try out Phase}

After the development of integrated reading prototype Pamanpintermu was accomplished, Focus Group Discussion was then conducted to validate the developed prototype. The discussion involved ten English teachers and ten students from SMAN 1 Gresik and SMA Muhammadiyah 1 Gresik, four English lecturers from English Education Department University of Muhammadiyah Gresik who teach reading class, and two programmers specialist in Java Script and PHP program from Informatics Department University of Muhammadiyah Gresik. The objective of the FGD was to invent validation score, feedbacks, and comments related to pre reading, whilst and post reading, audio, auto and manual scoring, integrated reading tasks, and software format before the developed prototyped was implemented into a try out phase.

The try our was conducted as part as FGD section with one and half hour section the students and the teacher were given an opportunity to use the prototype of Pamanpintermu reading and its auto assessment tools. Other participants in FGD took their roles as observers. After the try out finished, 10 students and 10 teachers were given an opportunity to give feedbacks on the discussion forum. At the end of the discussion all participants filled the validation checklist as well as their feedbacks.

\subsection{Final Product}

The final product was the developed and revised integrated reading prototype using PHP software and its instrument evaluation named as Pamanpintermu. It comprised fixed timed vocabulary survey, vocabulary audio, and its auto vocabulary scoring model. Second part consisted of fixed reading text, audio for listening and reading purposes, timed reading, dictionary text (DITEXT), manual scoring for reading errors and speed. The third part displayed fixed three different models of comprehensions tasks completed with auto scoring. The fourth part revealed fixed writing task taken from the passage. It introduced word formation and derivation construction with its auto scoring as well.

\section{Results, Development and Discussion}

\subsection{Need Analysis}

An open ended questionnaire comprising 10 item questions was distributed to 110 respondents respectively. Specifically it was given to 100 students and 10 English teachers from the two exemplary Senior High Schools to formulate their target and learning needs in integrating between reading and mobile use. The first question focused on the contribution of reading skill toward other English skills and components such listening, speaking, writing, pronunciation, vocabulary and grammar. Around $66 \%$ students and $100 \%$ teachers claimed that reading contributed to other English skills and components. The rest $18 \%$ students answered that reading contributed to other English skills, and 16 students responded the contribution of reading toward pronunciation, vocabulary, and grammar. The result of this point is in agreement with previous studies (e.g. Grgurovic, 2007; Montero-Fleta \& Perez-Sabater, 2010). They also have probed that reading significantly contributes toward both English skills and components.

The second question relied on teaching reading method. There were $27 \%$ students and $20 \%$ teachers claimed that they preferred teaching reading for the purpose of integrated skills simultaneously. Around $22 \%$ students and $40 \%$ teachers preferred to have isolated reading skill. Meanwhile $51 \%$ students and $40 \%$ teachers liked to implement teaching reading method through read, correct, and answer comprehension question through individual and collaborative learning. The finding is evidence that the traditional teaching reading strategies still implemented in EFL settings. In responding this view, Arifani (2016) suggests to implement round robin reading model where each student could improved their comprehension as they have more chances to practice and acquire more exposures.

The third question concerned on the objective of teaching reading. From the five options reading skill, comprehension, speed reading, phonetics and phonemics awarenes, the first and the second option correspondingly placed $46 \%$ and $54 \%$ students. Meanwhile, $60 \%$ teachers stated that the objective of teaching reading was just comprehension and the rest $40 \%$ concerned on phonetics and phonemics awareness. Referring to the need analysis finding on this point, all EFL teachers and students are not aware of reading international objective of reading. According to International Reading/Literacy Association, reading objectives covers skill, speed, comprehension, phonetics and phonemics awareness (Santa et al., 2000).

The fourth question concerned on reading assessment. Related to assessment forms, $46 \%$ students and $60 \%$ teachers claimed that reading comprehension was the most important aspect. The rest, $40 \%$ and $20 \%$ teachers 
implemented reading skill assessment and other $14 \%$ students and $10 \%$ teachers concerned on summarizing the content of the passage. In addressing toward the implementation of reading assessment Shepard (2000) and Stiggins (2008) state that assessment is not simply a matter of test but any data collected by the teachers to update a variety of decisions. Many aspects of assessment can be assess through reading such as reading skill or fluency, comprehension, speed, vocabulary and the psychological aspect of motivation in reading can be assessed as well (Bombly, 2013).

The fifth item focused on respondents' expectation toward the objective of teaching reading. There were $39 \%$ students and $70 \%$ teachers hoped that the goal of teaching reading should cover comprehension. The rest $26 \%$ students and $10 \%$ teachers focused on how to read the text and other $35 \%$ students and $20 \%$ teachers concerned on vocabulary toward the difficult words from the text and pronunciation. Toward the objective of teaching reading several studies underline the coverage of reading such as pronunciation (e.g Brett, 2004; Stockwell, 2007), vocabulary (e.g. Ma \& Kelly, 2006), and language skills (e.g. Montero-Fleta \& Perez-Sabater, 2010). Consequently, the finding of the study in term of coverage of reading objective is still far from the previous research studies.

The sixth question relied on the use of mobile use or reading software in teaching reading. It showed that $95 \%$ students and $90 \%$ teachers use mobile phone for the offline dictionary, TOEFL and IELTS from internet and CD. The rest $5 \%$ and $10 \%$ teachers did not use any mobile use programs for the teaching reading. One of the classical issues toward mobile application in EFL reading is internet connection access especially in developing country and also EFL teachers' perception toward the utilization of mobile use in their classes (Kim \& Rissel, 2008). One of the possible factors is teachers' understanding toward the use of mobile technology in reading is very low as stated in the result of the questionnaire. Teachers' ability in operating technology becomes another crucial factor toward the absence of technology in the classroom (Haswani, 2014).

The seventh question discussed on respondents' expectation toward the development of reading and mobile use. The result revealed that $100 \%$ students and $100 \%$ teachers expected to develop reading software completed with pre-reading exercise, reading text and its pronunciation, auto assessment and scoring for the purpose of integrated skills which could be operated in mobile phone and computer. The research findings are in agreement of the previous research on the coverage of reading objectives on pronunciation, vocabulary, and language skills (Brett, 2004; Stockwell, 2007; Ma \& Kelly, 2006)

The eighth question discussed on whilst reading activity. It showed that $43 \%$ students and $40 \%$ teachers wrote timed or speed reading monitor. The rest $20 \%$ students and $40 \%$ teachers responded reading comprehension and vocabulary tasks. The other $37 \%$ students and $20 \%$ teachers responded writing activity, speaking, listening, grammar, and vocabulary exercises. Meanwhile for the fulfilment of reading skills coverage through reading, the finding conform the previous study conducted by Montero-Fleta \& Perez-Sabater, 2010.

The ninth questions focused on text difficulty level. It showed that $25 \%$ students and $30 \%$ teachers expected the length of the text within $200-400$ words with $70 \%$ familiar vocabulary. Other $41 \%$ students and $40 \%$ teachers preferred to have the length of reading text within $400-500$ words with $60 \%$ familiar vocabulary. The rest $34 \%$ students and $30 \%$ teachers liked to have passage with the number of words around 500 words familiarity level of achieved $40 \%$. The finding of the text difficulty level meets the previous study conducted by Day (1994) toward the selection of EFL text, he mentioned several criteria namely relevance with curriculum, suitability with students' interests, cultural suitability, and length of the passage.

The tenth question focused on reading passage topics that they liked to discuss. It was found that $58 \%$ students and $60 \%$ teachers liked to discuss introducing self and other, congratulating, expressing sympathy recount and descriptive texts, and narrative stories. Meanwhile, the rest $42 \%$ students and $40 \%$ teachers preferred to discuss announcement, mythology story, cross culture, reports, and social problem. It is also in line with Arias (2007) states in selecting reading topics careful attention should be made to fulfil students learning needs, interest, English level, background knowledge, relevance and text content suitability with EFL English curriculum.

\subsection{Design}

This phase comprised three main activities, namely syllabus design, Pamanpintermu prototype design, and integrated reading activities and auto scoring. First, syllabus design was formulated through reviewing the existing syllabus with the result of the need analysis. The findings from the need analysis showed that several objective of analyzing texts structure as stated in the existing curriculum were eliminated as it was not relevant with the respondents' expectations. Further, it did not reflect text comprehension directly so this element was eliminated and substituted into vocabulary survey related to the topic of the text. Other elements such as comprehension, topics of reading text mostly remained the same because it became the central concern of 
reading comprehension. The following was shown one of examples of the formulation of competence standard and its indicators as part of the syllabus.

Table 1. An example of syllabus formulation part

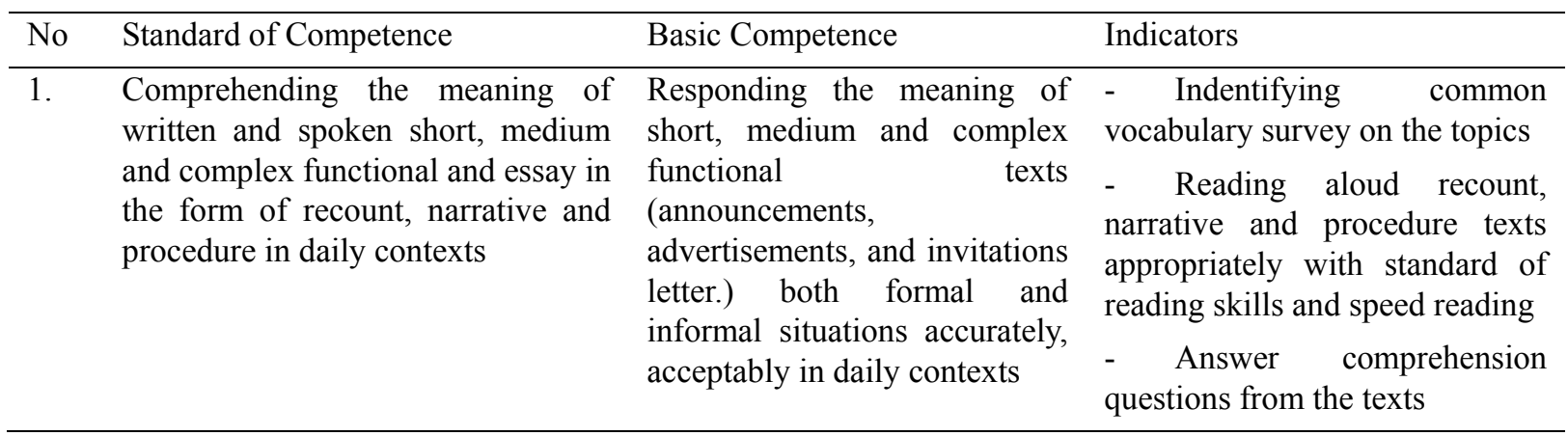

Second, the design of Pamanpintermu was also made using Personal Home Page (PHP) software that could be operated using mobile phone, tablet, and computer. It was design with the logo of Pamanpinter written in the login section. A login system was also designed to identify the name of each user and for the sake of auto scoring identification. The contents of the integrated software covered 10 vocabulary survey and its audio, 10 audio reading texts, 3 different types of vocabulary tasks and reading comprehension tasks, writing exercises, and 10 Dictionary texts (DITEXT).

Third, auto scoring model was also designed for measuring the indicator attainment in every section and exercise. This section contained auto scoring for vocabulary survey, manual scoring for timed or speed reading and manually inputted error reading identification score, and auto scoring for comprehensions tasks and writing sections. At the end of this section a summary of overall reading score was also displayed automatically.

\subsection{Development}

\subsubsection{Vocabulary Survey}

Vocabulary survey was developed to address students' problem on reading comprehension. It aimed at activating students' prior knowledge related to the topic of the reading passage in each unit. The development was inspired by "Family 100 Quiz" in one of Indonesian Television program where the score range between 1 until 100 depended on the top survey results. In this phase the vocabulary survey was adapted using the principle of objective test format. When the user typed correct answer they would get score 1 and 0 for each vocabulary survey result. The maximum points for this section obtained score 8 . Finally, the score would be automatically tabulated in detail scoring section. Vocabulary survey development results could be seen in the following figure. 

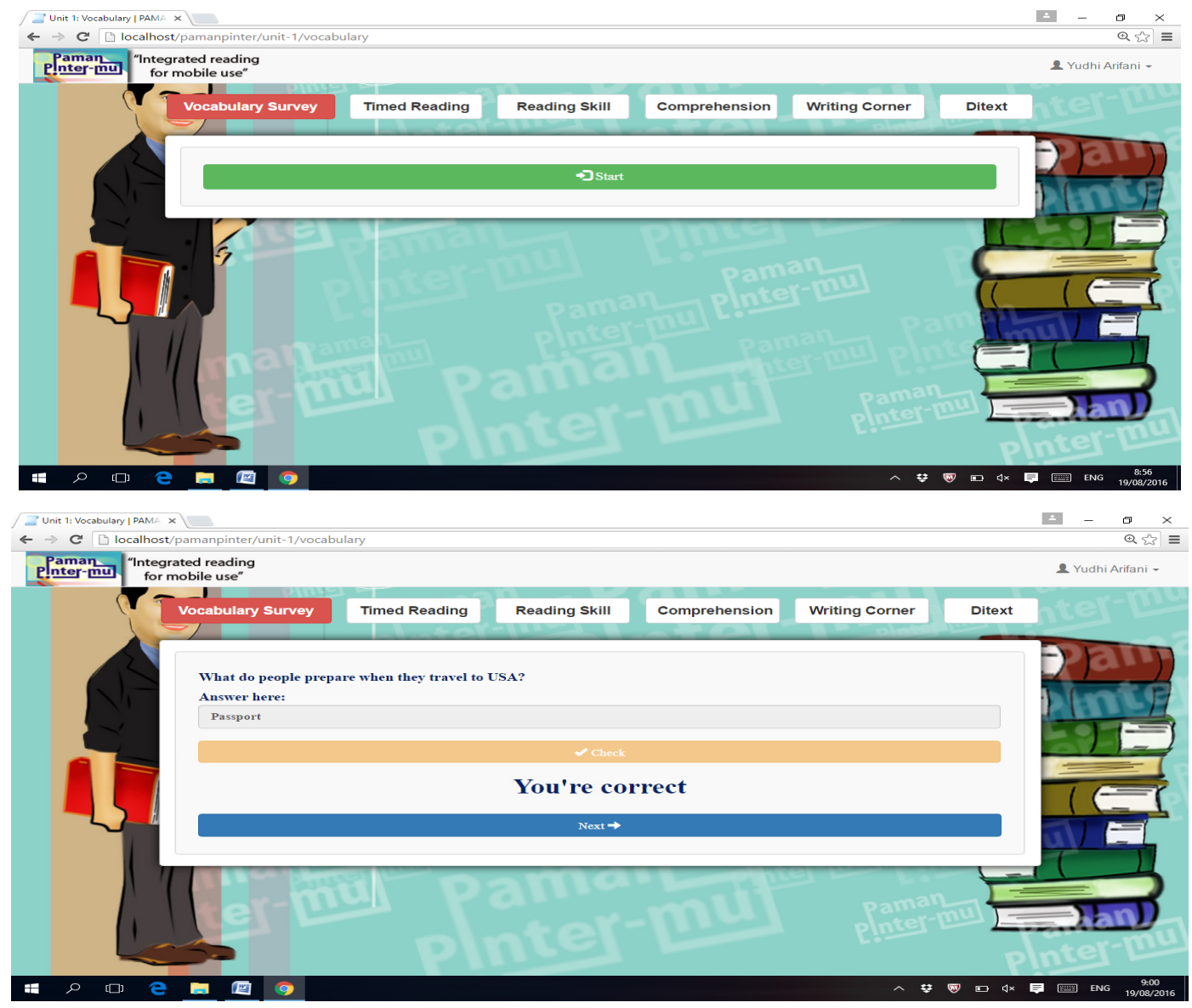

Figure 2. Vocabulary survey task

The above vocabulary survey section was also furnished with audio. An introductory audio was set and it would voice simultaneously when the user pressed start button until the first vocabulary survey question appeared on the screen. The questions consisted of 8 items where the correct answer would be scored into 1 and the wrong answer would be score 0 respectively. Next, responding audio would also voice when you finished typing each answer. The correct answer would be followed by an audio for appraisal and incorrect answer would result incorrect voice automatically from the program.

\subsubsection{Timed Reading}

This section offered whilst reading section which aimed at enhancing students' reading skill, fluency, and speed. Meanwhile the audio could be implmented as self-drilling and listening as well. So, the students could develop their listening ability step by step. Timed reading development could be seen in the following figure. 

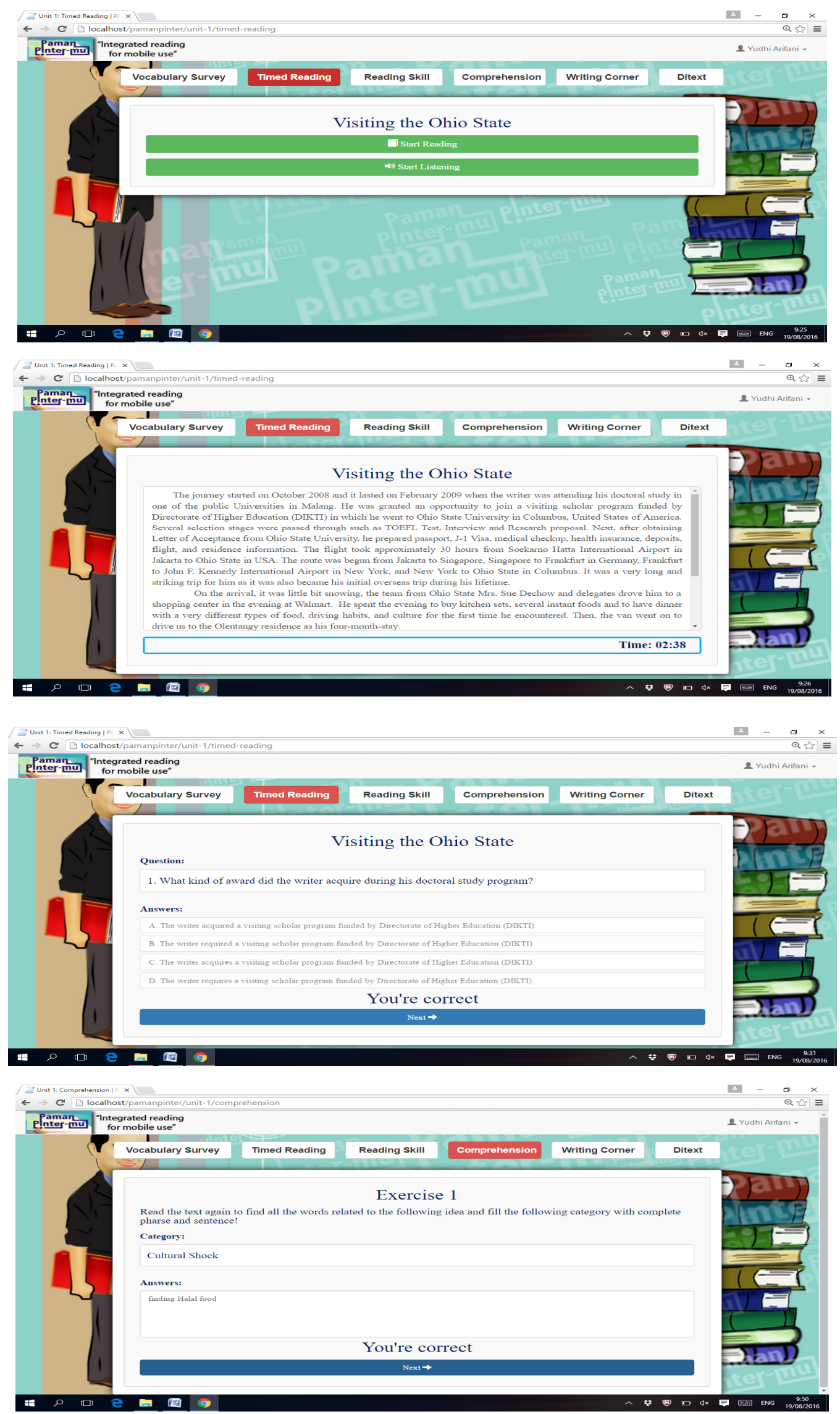

Figure 3. Timed reading section 
This part contained 10 units. Each reading section in each unit discussed different topics and all units were inserted with audio reading as well. The length of the passage varied in every unit. It ranged from 200 until 800 words. Each reading text was limited with timer following the normal time for International reading time within 250 words per minute. Beyond the set up time, the reading passage would automatically close. Consequently, students had to adjust their reading speed. The topics started from introducing self and other, expressing sympathy and congratulation, describing profession, overseas trip experiences, poetry, and cross culture understanding. These topics were self-creation and it did not adopt or adapt any resources. Comprehension question tasks were also presented step by step before the students dived into complex comprehension questions from the content of the whole text. Auto scoring model was also developed in this phase so the students could reflect their comprehension scores. Error reading detector tool was still developed manually by typing the number of reading error and time into the scoring box. As result, the score would be displayed simultaneously with other score results.

\subsubsection{Writing Focus}

This section was developed separately from reading activity. This part was furnished to train students' sensitivity on grammatical aspect and word formation in a sentence. The format of the task in this section was in the form of arranging scrambled sentence into meaningfully and grammatically correct sentence like in the following figure.

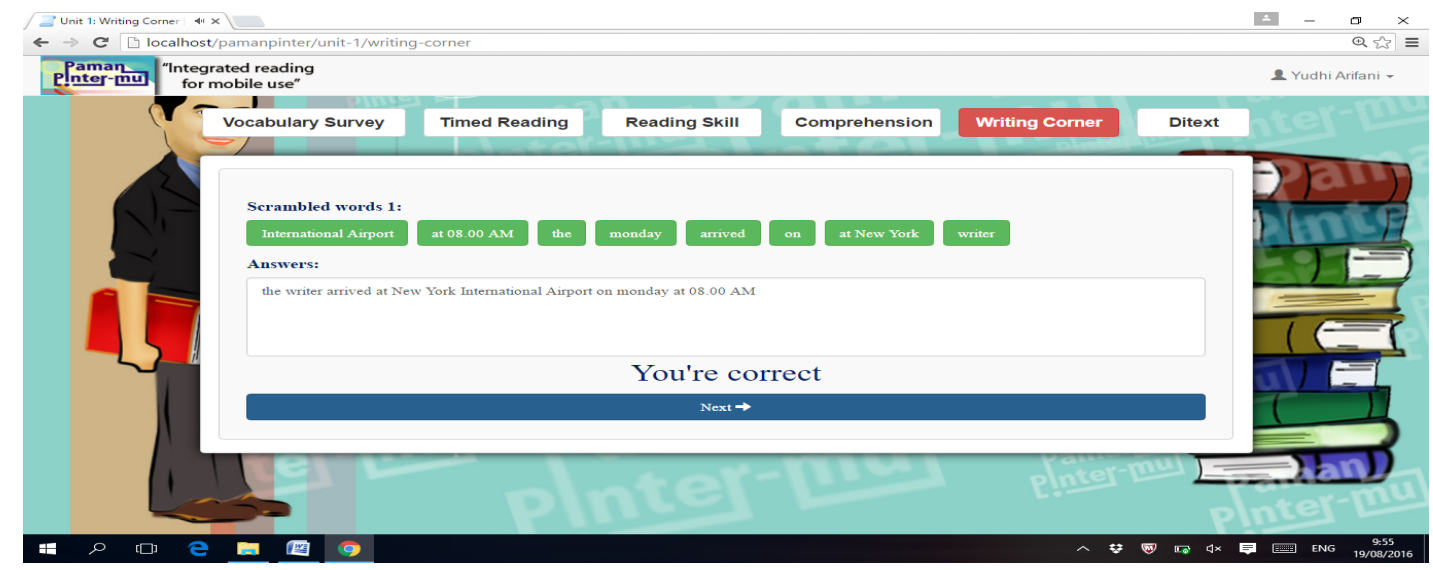

Figure 4.Writing focus

Word formation model in this section was offered based on the topic discussed in each unit. It was developed to help students develop their writing skill and guide them step by step to be more independent and automaticized. Therefore, this part was a stepping stone to train students to think more critically related to the discussed context before they were able to express their idea in writing. This section provided approximately 60 different word formation exercises. At the end of this part, the obtained score would be also automatically tabulated and submitted into whole scoring detail.

\subsubsection{Dictionary Text (DITEXT)}

This section called dictionary text (DITEXT). It functioned as a mirror to reflect students reading error when they were reading the passage individually. It also used as self-drilling to practice students' reading skill and fluency with the focus on pronunciation. The DITEXT section was presented in the following figure. 


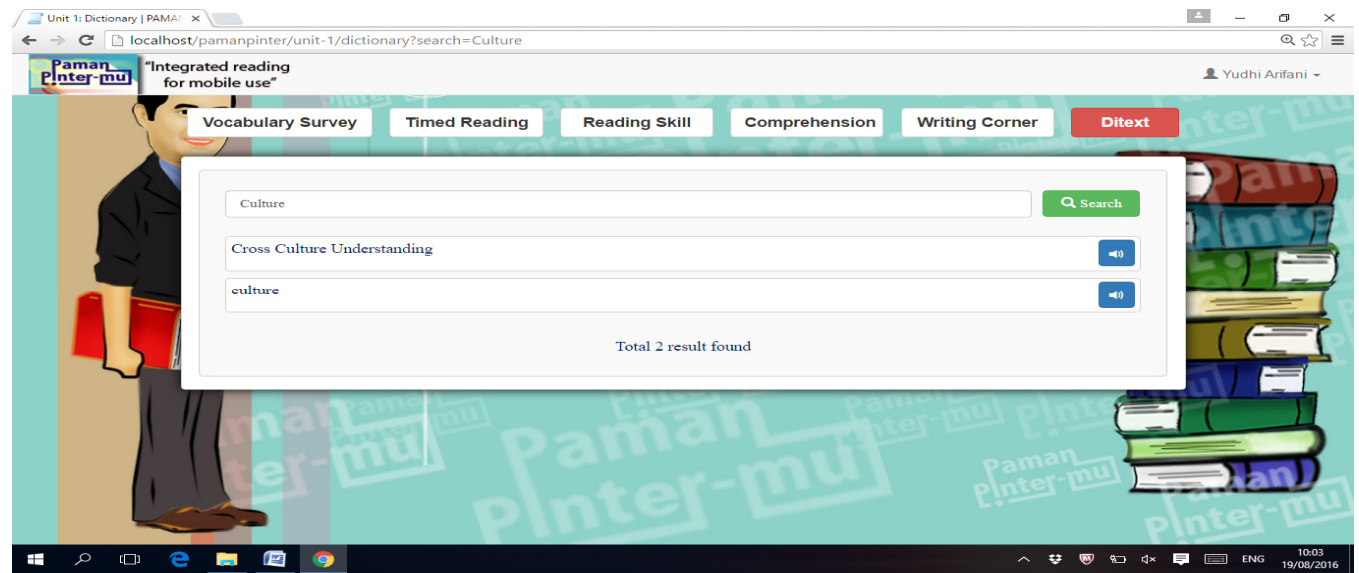

Figure 5. Dictionary text

The development of the DITEXT was done through manual way where each pronounced word from every text was edited using adobe audition and then adopted into the self-developed dictionary named as DITEXT. The researcher did not provide the translation as this section was used as self-reading fluency training. Meanwhile, reading comprehension was developed gradually in the previous section.

\subsubsection{Auto Scoring Detail}

This section contains all scores obtained from vocabulary survey, speed reading, error reading section, comprehension and writing exercises. All scores are collected and displayed automatically by the Pamanpintermu software. It is aimed at measuring students' ability toward overall reading program given inside of the software. The performance of the program is shown in the following table.

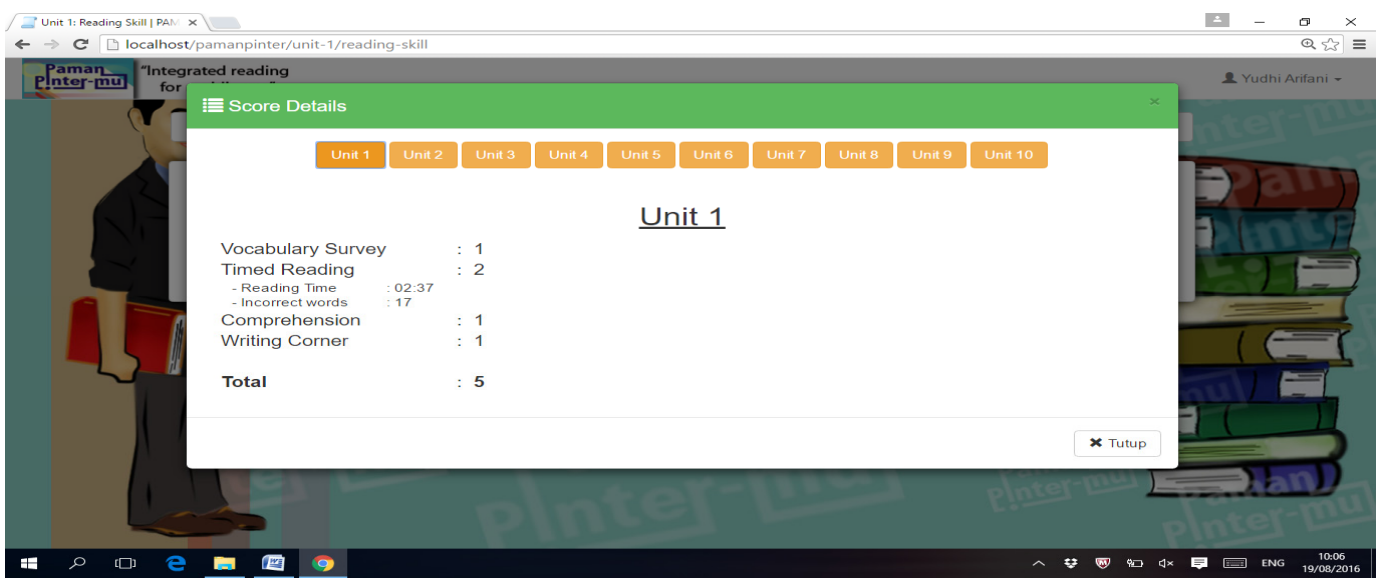

Figure 6. Auto score detail

The above describes overall reading abilities from each unit. It is aimed at gathering information toward the students' integrated reading abilities. Further, the information could be used by the teacher to provide more relevant and appropriate treatment for the students for the sake of their English improvement.

\subsubsection{Focus Group Discussion and Try out}

Focus Group Discussion was held to validate the developed prototype in terms of theoretical foundation and syntax, content relevance, difficulty level, exercise model, auto scoring and software practicality. The discussion involved ten English teachers and ten students from SMAN 1 Gresik and SMA Muhammadiyah 1 Gresik, four English lecturers from English Education Department University of Muhammadiyah Gresik, and two IT programmers specialist in Java script and PHP program. It was aimed at validating on the seven items elaborated in the above points. Validation checklist score varied from 1 to 4 indicated low to high level. The average score 
was obtained from the total scores of each validation divided by the number of validators Table 2 revealed the results of developed prototyped validation from the discussion.

Table 2. The result of prototype validation

\begin{tabular}{llll}
\hline No & Indicator & Average score & Validation Category \\
\hline 1 & Theoretical foundation & 3.7 & High \\
2 & Syntax & 3.7 & High \\
3 & Content relevance & 3.9 & High \\
4 & Difficulty level & 2.3 & Medium \\
5 & Integrated reading tasks & 3.6 & Medium \\
6 & Auto scoring & 3.8 & High \\
7 & Software practicality & 3.5 & High \\
\hline
\end{tabular}

The above table explained the theoretical foundation and its syntax from validators, it was found that the average score was 3.7 and it was categorized into high. Furthermore, content relevance achieved 3.9, it categorized into high and the difficulty level was in the medium level with the average score of 2.3. Meanwhile, the category of integrated reading skills and auto scoring obtained the average score of 3.6 and 3.8. The two categories belonged to high level. The last point, software practicality which was validated by two programmers achieved 3.5 and it went to high level as well.

The data from the reading experts showed that the developed prototype of Pamanpintermu reading categorized into high with the average score was 3.7 which meant good category to be used as reading material. Several feedbacks and suggestions such as punctuations and word choices were successfully furnished.

The data from English teacher toward the content of developed integrated reading in prototyped revealed that the average score was 3.9 better than the data obtained from reading experts. The feedback focus was stressed on the reading errors' detector section because it had to be done manually in detecting students' reading errors and speed.

The data from the students toward the overall reading activities and the software was categorized into high with the score of 3.7. The incoming comments were on vocabulary survey section where some survey results did not match with their answer because of unfamiliar terms used in it. Another feedback was similar to their teachers' response toward the auto error reading detector section.

\subsection{Final Product}

The final product was validated and revised based on the result of Focus Group Discussion (FGD) and the try out. It yielded an integrated reading program equipped with its auto scoring system named as Pamanpintermu. The program employed Personal Home Page software. It was developed using offline mode meaning that no internet connection was required. The program could be operated within Google Chrome by typing the site of local host/pamanpinter and it would automatically run after the driver was installed and the user logged in into the program. 


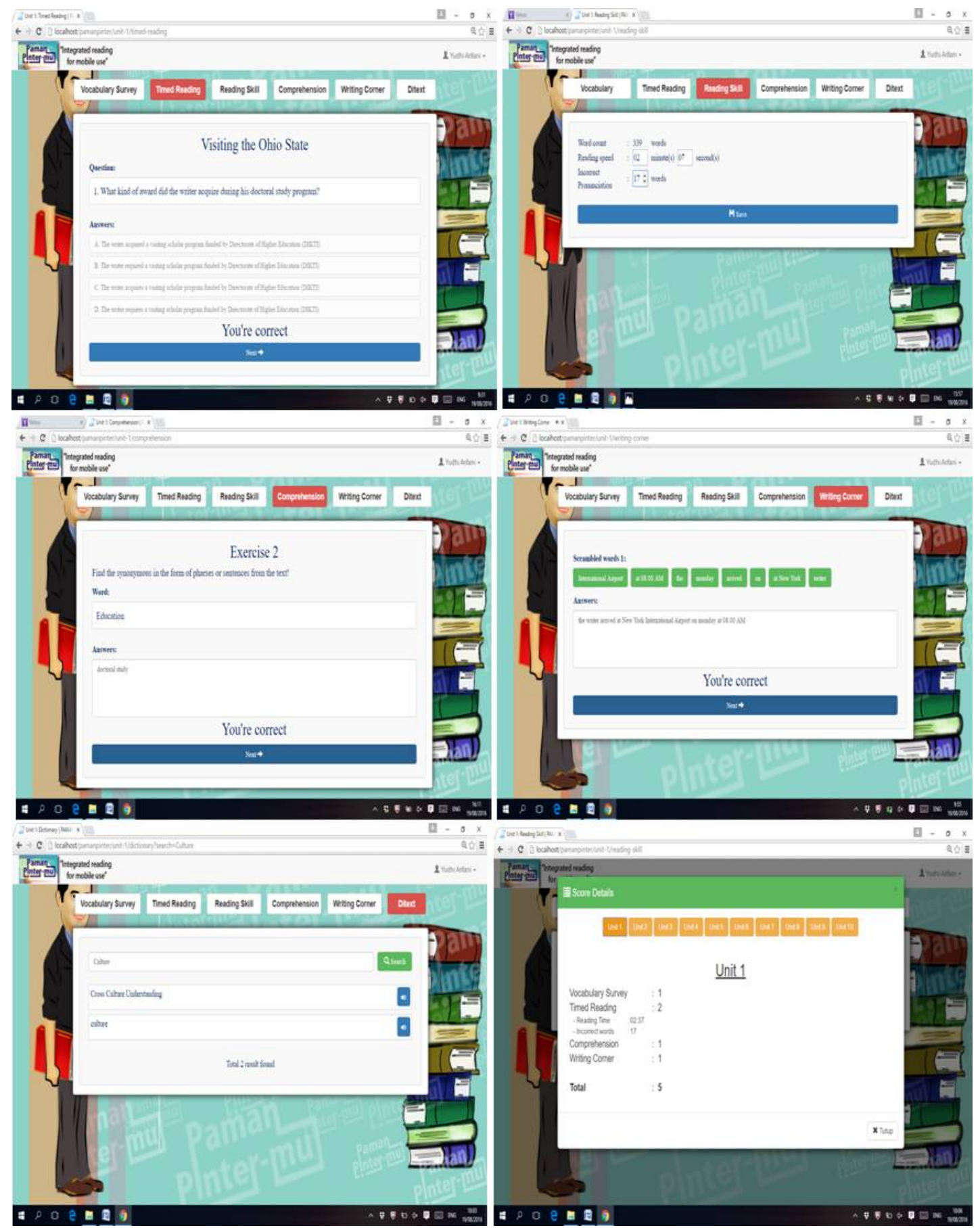

Figure 7. The prototype of Pamanpintermu integrated reading program

\section{Conclusion and Outlook}

This integrated reading software is developed to fulfill English teachers' and learners' needs to transform traditional teaching reading paradigm. The traditional teaching reading paradigm serves partially through read several lines of the reading text for each student in turn on by one, correct students reading error, deliver textual questions, and end up in commenting the result of answering question. Therefore, reading is not effective yet as it does not achieve whole reading objectives. This prototype offers an alternative solution to fill the gap. The product can be used as self-reading and collaborative reading for both inside and outside of classroom. Through this software, teacher can monitor student's individual reading skill, speed, comprehension, vocabulary, pronunciation simultaneously through the software more comprehensively and accurately. 
Related to the objective of teaching reading where most of the English teachers at Senior High Schools in Gresik are not aware of the comprehensive goals of teaching reading according to International Reading Association so it should be develop mutual relationship between related parties to address the issue. An intensive role of English teachers' forum to design effective teaching and learning EFL reading is required.

Referring to the overall outstanding prototype Pamanpintermu, there is one problematic point on the error reading detector section which cannot detect users' errors reading automatically as it requires further rigorous role from different background field of studies and specialists. Consequently, recommendation for further researchers to address this point would be worth contributing.

\section{Acknowledgements}

This research is part of Competitive Research Grant funded by the Ministry of Research and Technology, Directorate of Higher Education (RISTEK DIKTI). In addition, the writer would like to express his thanks to Indonesian Government through the Ministry of Research and Technology, Directorate of Higher Education, Board of Education in Gresik, Headmasters, English Teachers, and Students from SMAN 1 Gresik and SMA Muhammadiyah 1 Gresik.

\section{References}

Arias, J. I. (2007). Selecting reading materials wisely. LETRAS, 41, 131-151.

Arifani, Y. (2016). The implementation of team based discovery learning to improve students' ability in writing research proposal. International Education Studies, 9(2). http://dx.doi.org/10.5539/ies.v9n2p111

Arifani, Y. (2016). Optimizing EFL learners' sensitizing reading skill: Development of local content-based textbook. English language teaching, 9(5), 1-7. http://dx.doi.org/10.5539/elt.v9n5p1

Ahmed, M. D. (2015). The use of mobile phones in learning English by Sultan Qaboos University Students: Practices, attitudes and challenges. Canadian Journal on Scientific \& Industrial Research, 2(3), 143-152.

Al-Seghayer, K. (2013). The role of organizational devices in ESL readers' construction of mental representations of hypertext content. CALICO Journal, 24(3), 531-559.

Arena, C., \& Jefferson, C. T. (2008). Blogging in the language classroom: It doesn't "simply happen”. TESL-EJ, $4,1-7$.

Barraza, J. V. (2014). Using interactive graphical and technological strategies for EFL reading comprehension: A case study involving engineering students. Colombian Applied Linguistics Journal, 16(1). 29-39. $\mathrm{http}: / / \mathrm{dx}$. doi.org/10.14483/udistrital.jour.calj.2014.1.a-03

Becker, J. A. (2001). Clipart for language acquisition. TESOL Journal, 10(1), 28-30.

Brett, D. (2004). Computer generated feedback on vowel production by learners of English as a second language. ReCALL, 16(1), 103-113. http://dx.doi.org/10.1017/S0958344004000813

Chen, C. M., \& Hsu, S. H. (2008). Personalized mobile English vocabulary learning system for supportive effective English learning. Educational technology and society, 11(3), 153-180. http://dx.doi.org/10.1016/j.compedu.2007.06.011

Chinnery, G. M (2006). Emerging technology going to the MALL: Mobile Assisted Language Learning. Language Learning and Technology, 10 (1), 9-16.

Day, R. R. (1994). Selecting a passage for the EFL reading class. Forum, 31(1), 20.

Demouy, V., Eardly, A., Shrestha, P., \& Kukulska, H. A. (2011). The interactive oral assessment (IOA) project: Using Talkback skills in language. In: ICL 2011Ineractive collaborative learning.

Fisher, T., Pamberton, R., Sharpless, M., Ogata, H., Uosaki, N., Edmonds, P., ... Tschorn, P. (2009). Mobile learning of vocabulary from reading novels: A comparison of three modes. Paper presented at the proceeding of eighth world conference on moble and contextual learning, Orlando, Florida.

Foomani, M. E. \& H, M. (2016). A seamless learning design for mobile assisted language learning an Iranian context. English language teaching, 9(5), 8-21. http://dx.doi.org/10.5539/elt.v9n5p206

Gonzalez, D. (2007). Text-to-speech applications used in EFL context to enhance pronunciation. TESL-EJ, 11(2).

Grgurović, M., \& Hegelheimer, V. (2007). Help options and multimedia listening: Students' use of subtitles and the transcript. Language Learning \& Technology, 11(1), 45-66.

Halic, O. Lee, D., Paulus, T., \& Spece, M. (2010). To blog or not to blog: Students perception of blog 
effectiveness for leaning in a college-level course. Internet and Higher Education. http://dx.doi.org/10.1016/j.iheduc.2010.04.001

Haswani, F. (2014). The role of technology in EFL classroom. IJEE, 1(2), 107-118.

Hazaea, N. A., \& Alzubi, A. A. (2016). The effectiveness of using mobile on EFL learners' reading practices in Najran University. English language teaching, 9(5), 8-21. http://dx.doi.org/10.5539/elt.v9n5p8

Jarvis, H. \& Achilleos, M. (2013). From computer assisted language learning (CALL) to moile assisted language use. TESL-EJ, 16(4).

Jarvis, H., \& Krashen, S. (2014). Is CALL obsolete? Language acquisition and language learning revisited in a digital age. TESL-EJ, 17(4), 1-6.

Kennedy, C., \& Levy, M. (2008). L'italiano al telefonino: Using SMS to support beginners' language learning. ReCALL, 20(3), 315-330. http://dx.doi.org/10.1017/S0958344008000530

Kim, H. K., \& Rissel, D. (2008). Instructors' integration of computer technology: Examining the role of interaction. Foreign Language Annals, 41(1), 61-80. http://dx.doi.org/10.1111/j.1944-9720.2008.tb03279.x

Luu, T. T., \& Nguyen, D. T. M. (2010). Teaching English grammar through games. Studies in literature and language, 1 (7), 61-65. Retrieved from http:www.cscanada.org

Ma, Q., \& Kelly, P. (2006). Computer assisted language learning: design and evaluation. Computer Assisted Language Learning, 9(1), 15-45. http://dxdoi.org/10.1080/09588220600803998

Montero-Fleta, B., \& Perez-Sabater, C. (2010). A research on blogging as a platform to Enhance language skills. Procedia Social and Behavioral Sciences, 2, 773-777. http://dx.doi.org/10.1016/j.sbspro.2010.03.100

Nadera, K. A. (2001). Application of Computer Assisted Language Learning in the development of reading comprehension skills. MA thesis. IFA Interesting papers. Retrieved from http://elex.amu.edu.pl/ifa/interestingpapers/index.html

Naismith, L. (2004). Mobile technology ad learning. Future lab.

Peterson, M. (2012). EFL learner collaborative interaction in Second Life. ReCALL, 24(1), 20-39. http://dx.doi.org/10.1017/S0958344011000279

Pop, A. (2010). The impact of the new technologies in foreign language instruction: Our experience. Procedia: Social and Behavioral Science, 2, 1185-1189. http://dx.doi.org/10.1016/j.sbspro.2010.03.169

Ravichndran, T. (2000). Computer-assisted language learning (CALL) in the perspective of interactive approach: Advantages and apprehensions. Proceedings: National seminar on CALL. Retrieved from http://www.members.rediff.com/eximsankar/call.htm

Santa, C., Williams, C., Ogle, D., Farstrup, A., Au, K., Baker, B., ... Shanahan, T. (2000). Excellent Reading Teachers: A Position Statement of the International Reading Association. Journal of Adolescent \& Adult Literacy, 44(2), 193-199.

Shepard, L. (2000). The role of classroom assessment in teaching and learning. Center for the Study of Evaluation. Los Angeles, CA: UCLA Center for the Study of Evaluation.

Bombly, M. S. (2013). Reading assessment practices of elementary general education teachers: A descriptive study: Graduate Theses and Dissertations.

Smidt, E., \& Hgelheimer, V. (2004). Effects of online academic lecturers on ESL listening comprehension, incidental vocabulary acquisition, and strategy use. Computer Assisted Language Learning, 17(5), 517-556. http://dx.doi.org/10.1080/0958822042000319692

Stiggins, R. (2008). Assessment manifesto: A call for the development of balanced assessment systems. Portland, OR: ETS Assessment Training Institute.

Stockwell, G. (2007). A review of technology choice for teaching language skills and areas in the CALL literature. $\operatorname{ReCALL}, 19,105-120$. http://dx.doi.org/10.1017/S0958344007000225

Wang, S., \& Smith, S. Reading and grammar learning through mobile phones. Language Learning \& Technology, 17(3), 117-134.

Warschauer, M., \& healey, D. (1998). Computers and language learning: An overview. Language Teaching, 31, 57-71. http://dx.doi.org/10.1017/S0261444800012970

Yoon, H. (2008). More than a linguistics reference: the influence of corpus technology on L2 academic writing. 
Language Learning \& Technology, 12(2), 31-48.

\section{Copyrights}

Copyright for this article is retained by the author(s), with first publication rights granted to the journal.

This is an open-access article distributed under the terms and conditions of the Creative Commons Attribution license (http://creativecommons.org/licenses/by/4.0/). 